\title{
Modern Contraception: Uptake and Correlates among Women of Reproductive Age-Group in a Rural Community of Osun State, Nigeria
}

\author{
Ajibola Idowu ${ }^{1 *}$, Grace Chinyere Ukandu ${ }^{1}$, Jeremiah Mattu ${ }^{1}$, Damilola \\ Olawuyi $^{1}$, Adeola Abiodun ${ }^{1}$, Phillip Adegboye ${ }^{1}$, Chiamaka Chibu-Jonah ${ }^{1}$, Anita \\ Eseogene Siakpere $^{1}$, Esther Ishola ${ }^{1}$, Titilola Adeyeye ${ }^{1}$, Samuel Alabi ${ }^{1}$
}

\footnotetext{
OPEN ACCESS

Citation: Ajibola Idowu, Grace Chinyere Ukandu, Jeremiah Mattu, Damilola Olawuyi, Adeola Abiodun, Phillip Adegboye, Chiamaka Chibu-Jonah, Anita Eseogene Siakpere, Esther Ishola, Titilola Adeyeye, Samuel Alabi. Modern Contraception: Uptake and Correlates among Women of Reproductive AgeGroup in a Rural Community of Osun State, Nigeria. Ethiop J Health Sci.2020;30(4):531. doi:http:// dx.doi.org/ 10.4314/ejhs.v30i4.8

Received: January 11, 2020

Accepted: March 17, 2020

Published: July 1, 2020

Copyright: (C) 2020 Ajibola I., et al. This is an open access article distributed under the terms of the Creative Commons Attribution License, which permits unrestricted use, distribution, and reproduction in any medium, provided the original author and source are credited. Funding: Nil

Competing Interests: The authors declare that this manuscript was approved by all authors in its form and that no competing interest exists.

Affiliation and Correspondence:

${ }^{1}$ Department of Community Medicine,

Bowen University, Iwo, Nigeria

*Email: idajibola@yahoo.com
}

\section{ABSTRACT}

BACKGROUND: Universal contraceptive access is one of the key strategies for achieving sustainable developments in any country. Yet, uptake has remained low in most developing nations like Nigeria. The reasons for low use must be contextually understood to aid effective contraceptive programming. This study assessed contraceptive use and its determinants among reproductive aged women in Ejigbo, Osun State, Nigeria.

METHOD: A quantitative study involving 405 participants which were recruited using multi-stage sampling method was carried out. Data were collected using pretested semi-structured, intervieweradministered questionnaire. Chi-Square test and binary logistic regression analysis were used for inferential statistics.

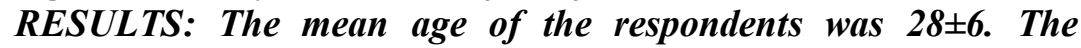
majority (92.8\%) of the respondents were aware of family planning, 68.9\% of them possessed good knowledge but only 53\% of them demonstrated favorable contraceptive attitude. Less than half (33.0\%) of those who had heard about contraception were current users of modern methods. Injectables (45.0\%) and male condoms (30.0\%) were the most prevalent contraceptive methods among the respondents. The main determinants of contraceptive uptake were respondents' educational status (AOR=0.525, 95\%CI $=0.284-0.972)$, contraceptive knowledge $(\mathrm{OR}=0.512$, 95\%CI $=1.242-1.968)$ and attitude $(\mathrm{OR}=0.512,95 \% \mathrm{CI}=1.242-$ 1.968). Fear of perceived side effects (45.2\%), low pregnancy risk perception (35.7\%) and spousal refusal (12.5\%) were the main reasons for non-contraceptive use among non-users.

CONCLUSION: Contraceptive demand in the study population was low in spite of high awareness level. There is a need to increase contraceptive literacy in the study population and make the services more acceptable to rural dwellers so as to meet the $S D G-3$ target in Nigeria.

KEYWORDS: Contraception, family planning, knowledge, attitude, practice, uptake, Nigeria 


\section{INTRODUCTION}

Voluntary control of fertility has become of paramount importance to every facet of modern society particularly due to its ability to slow down population growth and indirectly improve national economic growth. The world has continued to witness exponential growth of its population as it has been projected to reach 9.8 billion people by 2050 (1). Most of these growths have been occurring in the developing countries which have minimal resources to match, thereby perpetrating the circle of poverty in those countries. Among the most populous countries in the world, Nigeria is growing at the fasted rate with a current population of about 200 million people (ranking $7^{\text {th }}$ in the world) (1). Meanwhile, contraception is a key strategy of controlling this upward trend in population growth by helping to prevent unwanted and unplanned pregnancies. Asides this, adequate contraceptive utilization has the potential to reduce the rate of unwanted/unintended pregnancies and unsafe abortion. This is of paramount importance particularly in rural areas where women are mostly vulnerable to adverse pregnancy and delivery outcomes due to poor quality of maternal healthcare services available to them.

Contraceptive access is intricately related to its utilization. Thus, the United Nations has recommended that nations should ensure universal access to sexual and reproductive health care services including family planning information and education in order to achieve target-7 of the Sustainable Development Goal (SDG)-3 (2). Contraceptive access can be described in terms of its physical access, availability, acceptability, affordability and accommodativeness. It is also recommended that nations should ensure integration of reproductive health services into national developmental strategies and programs (3). Family planning service has indirect benefits of reducing maternal mortality rate (MMR) in a country by eliminating unsafe abortions which often result from unintended pregnancies.

Every year, over 40,000 women in Nigeria die from childbirths and pregnancy related complications (4). Thus, while Nigeria is responsible for only $2.5 \%$ of the world's population, it accounts for $14 \%$ of global maternal deaths every year (3). There has not been significant reduction in MMR in Nigeria considering the National Demographic and Health Survey (NDHS) reports from 2008-2018 (545,576 and 512 deaths per 100,000 live births) (4-6). This is deviant to SDG 3.1 target of reducing global MMR to as low as 70 deaths per 100,000 livebirths (2).

Improving contraceptive uptake among women of reproductive age in Nigeria is thus critical for reversing this situation. However, the 2018 NDHS reports that only $12 \%$ of Nigerian women currently use a modern form of contraception resulting in high rates of unwanted/unplanned pregnancies, unsafe abortions (6). In 2012, the rate of unintended pregnancies in Nigeria was estimated at 59/1,000 of women aged 15-49 by Bakole et al. The study also estimated that about 1.25 million induced abortion were recorded within the same year (7).

Studies have revealed variations in the types of contraception preferred by Nigerian women and their determinants $(6,8)$. Most of the studies have focused on residents of urban communities with a few of them targeting rural dwellers (810). Meanwhile, uptake of family planning services has been low for rural dwellers compared to their urban communities possibly due to disparity in their socio-cultural and socioeconomic characteristics $(6,11)$. Moreover, there has been rural-urban differential in the demand for modern contraception as revealed by the 2018 NDHS, thus creating conspicuous knowledge gap as to the factors which may be responsible for this observed variation.

The rural-urban disparity in access to contraception is a global phenomenon which is part of the reasons for the launch of the United Nations' FP2020 programme with the aim of reaching at least 20,000 underserved people with contraceptive services by year 2020(12). There is currently paucity of information on demandrelated barriers to modern contraceptive use in most Nigerian rural communities. Thus, the current study sought to bridge this gap in knowledge and provide useful baseline information for policy makers in the field of 
reproductive health, to develop cost-effective family planning interventions to increase its uptake among the rural dwellers. The study assessed contraceptive knowledge, attitude and determinants of women in reproductive age group in Ejigbo, Osun State, Nigeria.

\section{MATERIALS AND METHODS}

This study which employed cross-sectional design was conducted among women of reproductive age group in Ejigbo community, the administrative capital of Ejigbo Local Government Area (LGA), Osun State, Nigeria. The population of the LGA is estimated to be 150,610 (13), comprising predominantly of farmers and people of Yoruba ethnic group. The predominant religions in the community are Islam, Christianity and Traditional. The community has four (4) accredited healthcare facilities for provision of family planning services at least once each week. Well-trained healthcare personnel such as Nurses and Community Health Officers (CHOs) are available in those facilities to attend to clients. However, there are many chemists' shops where some family planning methods (such as male condom and emergency contraceptive pills) are obtained over-the counter. Occasionally, outreach programmes where condoms are distributed to participants occur in the community.

All women between 15-49 years of age, who were permanent residents of Ejigbo community and who consented, were allowed to participate in the study. Eligible women adjudged to have health challenges which could prevent them from giving valid responses to our questions were exempted from the study.

Our sample size was calculated using Leslie Kish formula for estimating sample size in a population which is greater than 10,000 people. The standard normal deviate was set at 1.96, which corresponds to $95 \%$ confidence level. We assumed that $25.4 \%$ of our study participants would be using modern contraceptives based on report from a study conducted in Oyo State, Nigeria, in 2017 by Adeyemi et al(14). The margin of error was set at $5 \%$, and $10 \%$ non- response rate was envisaged and correction for this was made. The sample size was multiplied by 1.2 to correct for cluster effect, and a total of 420 questionnaires were administered to increase the representativeness of our study.

Multistage sampling method was used in recruiting our eligible respondents. Firstly, two out of eleven electoral wards in Ejigbo LGA were selected by simple random method (balloting). Secondly, two Enumeration Areas (EAs), each from the chosen electoral wards, were selected by simple random technique Next, two streets each were selected via balloting from the two selected EAs. All the households on a street with eligible respondents were visited for interview. In a household with more than one eligible respondent, one was selected by simple random method.

Data were collected using intervieweradministered, semi-structured questionnaire which was developed after reviewing previous similar studies. The instrument collected information on respondents' socio-demographic characteristics, their contraceptive knowledge, attitude, and uptake as well as barriers to modern contraception. The questionnaire was written in simple English for easy understanding. Translation into Yoruba language was done for respondents who preferred answering our questions in their native language, backtranslation into English language was done to preserve original meanings of the questions. Data were collected by a group of 10 medical students who were trained on questionnaire administration in rural communities.

A pretest exercise was carried out in a different population -among 40 women of reproductive age group in Ife-Odan, using convenience sampling method. The process assisted us in strengthening the internal validity of our instrument. Irrelevant or ambiguous questions noticed were either rephrased or entirely removed in line with our study objectives.

There was daily editing of each questionnaire before data entry into Statistical Package for Social Sciences (IBM SPSS 21.0) for analysis. Data were presented in tables and 
charts. Mean and standard deviation were used to summarize numerical data while Chi-Square test was used to compare categorical variables. Binary logistic regression was used to examine factors that were significantly associated with current contraceptive use among the respondents. Included variables in the regression model were those which were either statistically significant at bivariate level or had been reported as strong determinants of contraceptive uptake. A 95\% confidence interval was estimated for each variable to determine whether they were significant predictors of modern family planning use.

Awareness of respondents on contraception was assessed by asking if they had ever heard of modern contraception, and if they could correctly mention at least two contraceptive methods. However, knowledge on contraception was assessed using a scoring system. To do this, eight questions were asked; correct response to each of the questions attracted 1-point while wrong answers attracted 0-point. The mean knowledge score and standard deviation (SD) was calculated and was found to be $5 \pm 1.5$. Those with the mean score of 3.5 or less were categorized as having poor knowledge, those with score between 3.6 to 6.5 were classified as having fair knowledge while those with at least 6.6 were grouped as having good knowledge.

Attitude of respondents to contraception was assessed using a 5-point Likert-scale ranging from strongly agreed (5 points) to strongly disagreed (1 point). In doing this, 10 questions were positively phrased on contraception. Th maximum score obtainable was 50 points and the median score $\left(50^{\text {th }}\right.$ percentile $)$ was estimated. The median value was 27 and the range was 30 (4515). Respondents who scored below the $50^{\text {th }}$ percentile were classified as having negative attitude while those who scored above the median value were grouped as people with positive attitude to contraception.

Ethical approval to conduct the study was sought from the Ethical Review Committee of Bowen University Teaching Hospital, Ogbomoso,
Nigeria. Permission was also obtained from the community head and his cabinet members before commencing the study. Written consents were obtained from each respondent before they were allowed to participate in the study. Participation in the study was entirely voluntary, and participants were allowed to opt out at any stage of the interview as they so wished. Responses from the interviewees were kept strictly confidential as the questionnaires were made anonymous and data collected were entered into passworded computers.

\section{RESULTS}

A total of 420 questionnaires were administered, but 405 of them were returned satisfactorily completed (response rate of 96.4\%). The mean age of the respondents was $28 \pm 6$. Most (38.8\%) of the respondents were 20-29 years of age, $64.2 \%$ of them were married and $52.1 \%$ had secondary education. Most $(60.2 \%)$ of the respondents practiced Islamic religion. Most $(63.0 \%)$ of the respondents had 1-2 children, $26.0 \%$ had more than 4 children and the mean number of children was $1.2 \pm 0.8$. More than half $(55.3 \%)$ of the respondents earned less than $30,000.00$ Naira (\$81.74) monthly which is the current national minimum wage in Nigeria (Table $1)$.

From Table 2, 92.8\% of the respondents were aware of family planning by correctly mentioning at least two contraceptive methods, most $(47.0 \%)$ obtained their information from hospital staff. While $49.1 \%$ of them knew both men and women could use family planning, $44.1 \%$ stated that only women could benefit from family planning services. Almost three-quarters $(71.2 \%)$ of the respondents knew there could be side effects of using family planning methods. Whereas $68.6 \%$ of the respondents possessed good knowledge of family planning, only $54.3 \%$ of them demonstrated favorable attitude to using family planning. 
Table 1: Sociodemographic Characteristics of Respondents

\begin{tabular}{|c|c|c|}
\hline Variable & $\begin{array}{l}\text { Frequency } \\
\mathrm{N}=405\end{array}$ & Percent (\%) \\
\hline \multicolumn{3}{|l|}{ Age (Years) } \\
\hline$\leq 19$ & 91 & 22.4 \\
\hline $20-29$ & 157 & 38.8 \\
\hline $30-39$ & 97 & 24.0 \\
\hline$\geq 40$ & 60 & 14.8 \\
\hline \multicolumn{3}{|l|}{ Marital status } \\
\hline Single & 138 & 34.1 \\
\hline Married & 260 & 64.2 \\
\hline Divorced/Separated & 0 & 0.0 \\
\hline Widowed & 7 & 1.7 \\
\hline \multicolumn{3}{|l|}{ Level of education } \\
\hline No formal education & 70 & 17.3 \\
\hline Primary & 63 & 15.6 \\
\hline Secondary & 211 & 52.1 \\
\hline Tertiary & 61 & 15.1 \\
\hline \multicolumn{3}{|l|}{ Religion } \\
\hline Christianity & 160 & 39.5 \\
\hline Islam & 244 & 60.2 \\
\hline Traditional & 1 & 0.2 \\
\hline \multicolumn{3}{|l|}{ Parity } \\
\hline None & 75 & 18.5 \\
\hline $1-2$ & 255 & 63.0 \\
\hline $3-4$ & 49 & 12.1 \\
\hline$>4$ & 26 & 6.4 \\
\hline Mean & $1.2 \pm 0.8$ & \\
\hline \multicolumn{3}{|c|}{ Average family monthly income (Naira) } \\
\hline$\leq 30,000.00$ & 224 & 55.3 \\
\hline $31,000.00-60,000.00$ & 120 & 29.6 \\
\hline $61,000.00-90,000.00$ & 47 & 11.6 \\
\hline$\geq 91,000.00$ & 14 & 3.5 \\
\hline
\end{tabular}

In all, $42.5 \%$ of the respondents had ever used contraceptives but only $33.0 \%$ of them were current users. Among non-users, the most commonly mentioned barrier to contraceptive use were fear of perceived side effects $(45.2 \%)$, low pregnancy risk perception $(35.7 \%)$ and spousal refusal $(12.5 \%)$. 
Table 2: Respondents' Knowledge Attitude and Practice of Modern Contraception

\begin{tabular}{|c|c|c|}
\hline VARIABLE & $\begin{array}{l}\text { FREQUENCY } \\
N=405\end{array}$ & PERCENT (\%) \\
\hline \multicolumn{3}{|l|}{ Awareness of family planning } \\
\hline Yes & 376 & 92.8 \\
\hline No & 29 & 7.2 \\
\hline \multicolumn{3}{|l|}{ Sources of information } \\
\hline Hospital staff & 178 & 47.0 \\
\hline Mass media & 115 & 30.3 \\
\hline Family\& Friends & 80 & 21.1 \\
\hline Others & 6 & 1.6 \\
\hline Knowledge on who could receive family planning & $n=376$ & \\
\hline Men only & 23 & 6.2 \\
\hline Women only & 164 & 44.1 \\
\hline Both men and women & 189 & 49.7 \\
\hline Knew if there are side effects of family planning & $n=376$ & \\
\hline Yes & 269 & 71.2 \\
\hline No & 67 & 18.0 \\
\hline Don’t know & 40 & 10.8 \\
\hline Overall knowledge on family planning & $N=376$ & \\
\hline Poor & 88 & 23.4 \\
\hline Fair & 30 & 8.0 \\
\hline Good & 258 & 68.6 \\
\hline Attitude of respondents to family planning & $\mathbf{N}=376$ & \\
\hline Positive & 204 & 54.3 \\
\hline Negative & 172 & 45.7 \\
\hline Ever use contraception & $\mathrm{N}=376$ & \\
\hline Yes & 160 & 42.5 \\
\hline No & 216 & 57.5 \\
\hline \multicolumn{3}{|l|}{ Current contraceptive use } \\
\hline Yes & 133 & 33.0 \\
\hline No & 272 & 67.0 \\
\hline Barriers to contraceptive use among non-users & $\mathbf{N}=\mathbf{2 7 2}$ & \\
\hline Fear of perceived side effects & 123 & 45.2 \\
\hline Perceived low pregnancy risk & 97 & 35.7 \\
\hline Spousal disapproval & 34 & 12.5 \\
\hline Had enough children already & 4 & 1.5 \\
\hline Religious factor & 4 & 1.5 \\
\hline Others & 10 & 3.6 \\
\hline
\end{tabular}

Injectables and male condoms were the most prevalent contraceptive methods among the respondents. They were used by $45.0 \%$ and $30.0 \%$ of the current contraceptive users respectively (Figure 1). The most commonly identified side effect of contraception was weight gain which was mentioned by $55.0 \%$ of the current users (Figure 2). In Table 3,65.0\% of women with more than four children were non- contraceptive users. Respondents with no formal education were significantly less likely to have used contraception compared to their educated counterparts $(\mathrm{AOR}=0.525,95 \% \mathrm{CI}=0.284-0.972)$. Likewise, those with poor knowledge and negative attitude had significantly lesser odds of modern contraceptive use $(\mathrm{OR}=0.512$, $95 \% \mathrm{CI}=1.242-1.968 \quad$ and $\quad \mathrm{OR}=0.158$, $95 \% \mathrm{CI}=0.261-0.874)$. 


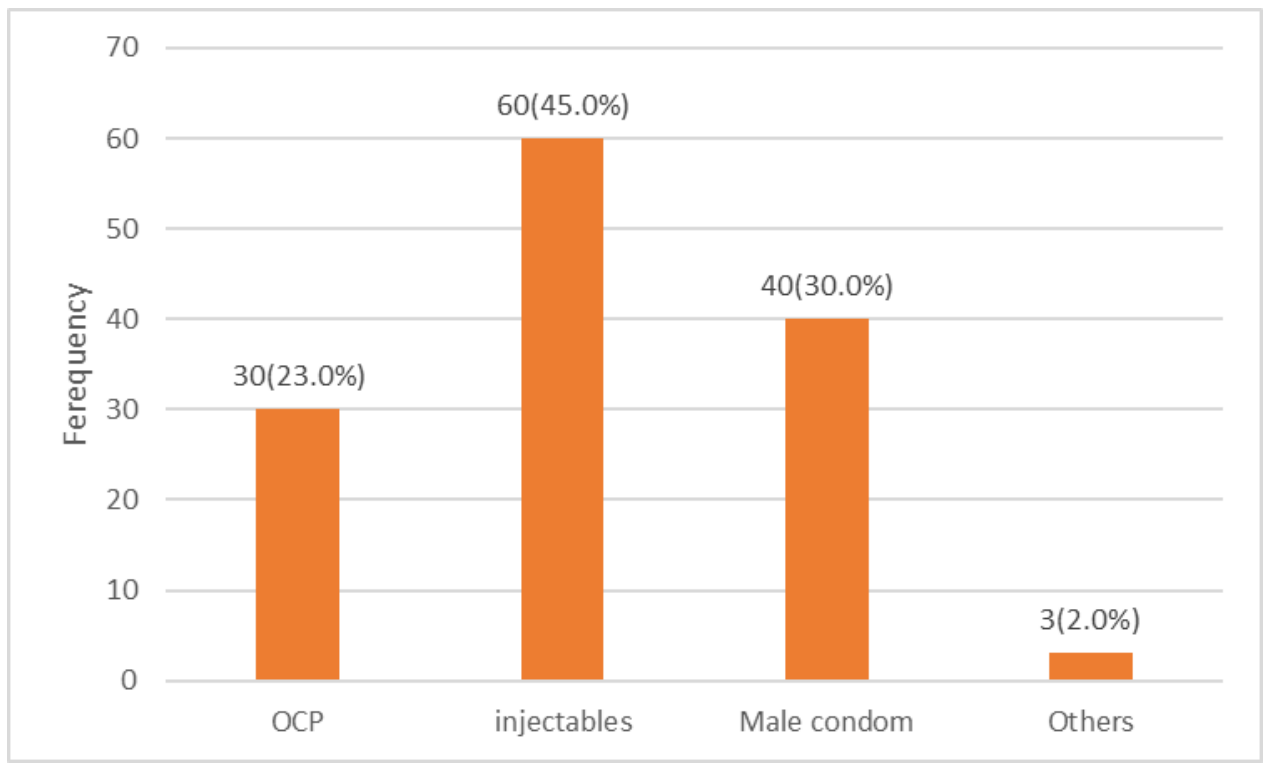

Figure 1: Types of modern contraceptive methods used by respondents

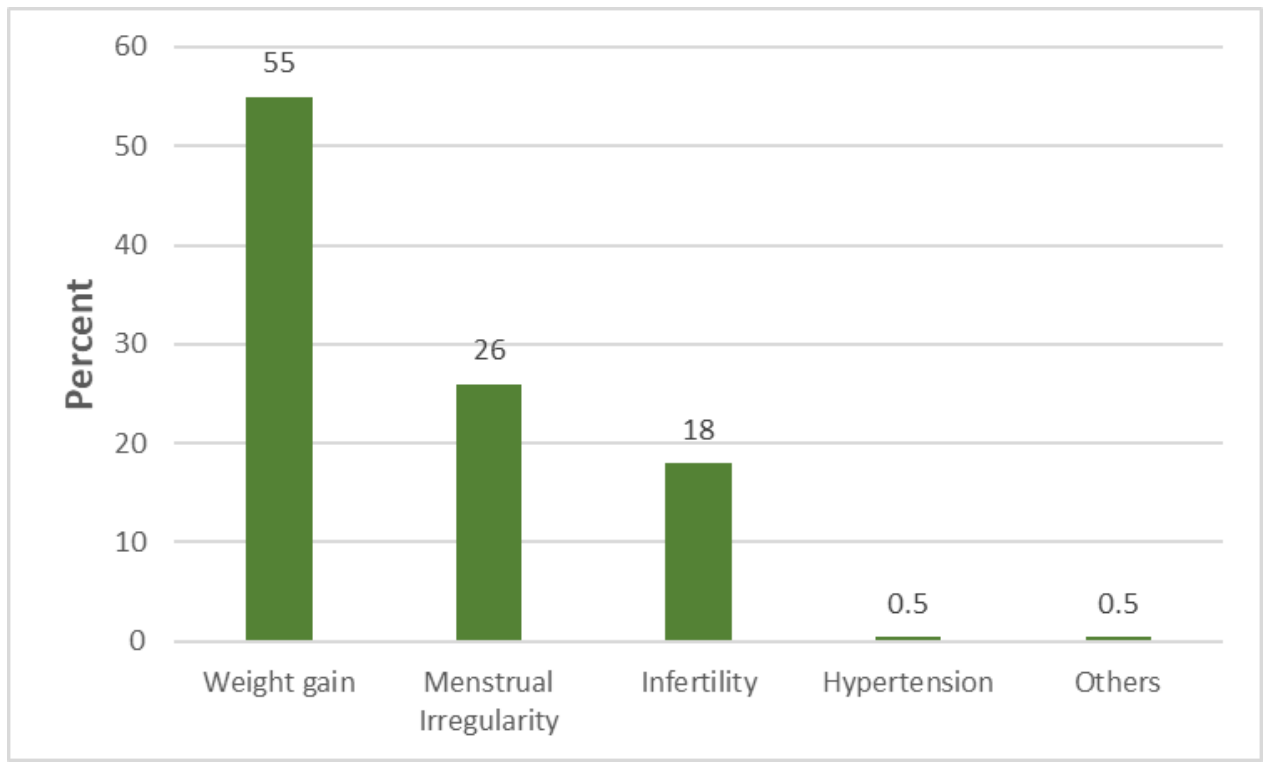

Figure 2: Side effects of family planning identified by contraceptive us

DOI: http://dx.doi.org/10.4314/ejhs.v30i4.8 
Table 3: Determinants of Current Contraceptive Use among the Respondents

\begin{tabular}{|c|c|c|c|c|c|c|c|}
\hline Variable & $\begin{array}{l}\text { Currently } \\
\text { planning } \\
\text { Yes } \\
\text { n= } \\
(\%) \\
(\%)\end{array}$ & $\begin{array}{l}\text { on Family } \\
\text { No } \\
n=272(\%)\end{array}$ & Total & $\chi^{2}$ & P value & $A O R$ & $95 \% C I$ \\
\hline Age (Years) & & & & 3.361 & 0.067 & 0.674 & $0.442-1.029$ \\
\hline$\leq 29$ & $73(29.4)$ & $175(70.6)$ & 248 & & & & \\
\hline$\geq 30$ & $60(38.2)$ & $97(61.8)$ & 157 & & & & \\
\hline \multicolumn{8}{|l|}{$\begin{array}{l}\text { Number of living } \\
\text { children }\end{array}$} \\
\hline $0-4$ & $124(37.5)$ & $207(62.5)$ & 331 & 18.057 & 0.066 & 1.501 & $0.672-3.4110$ \\
\hline$>4$ & $9(8.1 \%)$ & $65(91.9)$ & 74 & & & & \\
\hline Marital status & & & & 3.617 & 0.057 & 0.650 & $0.416-1.015$ \\
\hline Married & $39(26.9)$ & $106(73.1)$ & 145 & & & & \\
\hline Others & $94(36.2)$ & $166(63.8)$ & 260 & & & & \\
\hline Level of education & & & & 4.306 & 0.038* & 0.525 & $0.284-0.972$ \\
\hline Uneducated & $15(22.1)$ & $53(77.9)$ & 68 & & & & \\
\hline Educated & $118(35.0)$ & $219(65.0)$ & 337 & & & & \\
\hline Monthly Income & & & & 0.014 & 0.905 & 0.975 & $0.643-1.479$ \\
\hline$\leq 30,000.00$ & $73(32.6)$ & $151(67.4)$ & 224 & & & & \\
\hline$>31,000.00$ & $60(33.1)$ & 121(66.9) & 181 & & & & \\
\hline $\begin{array}{l}\text { Knowledge on } \\
\text { contraception }\end{array}$ & & & & 7.032 & $0.001 *$ & 0.512 & $1.242-1.968$ \\
\hline Poor & $30(25.4)$ & $88(74.6)$ & 118 & & & & \\
\hline Good & $103(39.5)$ & $158(60.5)$ & 261 & & & & \\
\hline $\begin{array}{l}\text { Attitude to } \\
\text { contraception }\end{array}$ & & & & 3.88 & $0.023 *$ & 0.158 & $0.261-0.874$ \\
\hline Negative & $26(15.0)$ & $149(85.0)$ & 175 & & & & \\
\hline Positive & $107(53.0)$ & $97(47.0)$ & 204 & & & & \\
\hline
\end{tabular}

*Statistically significant at $\mathrm{p}<0.05, \mathrm{AOR}=$ Adjusted odds ratio, $\mathrm{CI}=$ Confidence interval

\section{DISCUSSION}

The current study assessed knowledge, attitude and determinants of family planning use in a rural community of Nigeria. Almost all of the respondents were aware of family planning. High awareness level is expected to be associated with good knowledge of modern contraception, but this was not the case in the current study as $68.6 \%$ of the respondents had good knowledge. Slightly above half of the respondents had positive attitude towards modern contraception despite high awareness level. This is not unexpected since awareness has been shown to be a poor predictor of the behavioural domain of attitude (15). Thirty-three percent of the respondents were current contraceptive users. Our finding agrees with previous studies. For instance, a study by Adeyemi et al., in Ogbomoso, Nigeria, in 2016, revealed that all of the respondents were aware of contraception, but only $49.7 \%$ had ever used a method while $25.4 \%$ were current users (14). In another study conducted among Nigerian women attending antenatal clinic in Jos by Utoo et al., awareness level was $88.1 \%$, but only $44.0 \%$ were modern contraceptive users (16). However, the modern contraceptive prevalence rate $(\mathrm{mCPR})$ in the 
current study was much higher than the $12.0 \%$ reported by the 2018 NDHS (6) and 13.0\% mCPR reported by Monjok et al in 2010 (17). The reason for the higher $\mathrm{mCPR}$ in the current study could have been due to a relatively high literacy rate of the respondents as $67.2 \%$ of them had at least a secondary education. However, the low $\mathrm{mCPR}$ recorded in the current study and other Nigerian studies is of public health importance since it could have been responsible for the high rate of unintended pregnancies and unsafe abortions in the country as reported by Bakole et al (7).

Respondents' educational status, contraceptive knowledge and attitude were the main variables that were significantly associated with contraceptive uptake in the current study. A similar study conducted by Kasa et al., among women in resource limited area of Ethiopia corroborates our findings (18). Also, findings from the study conducted by Mitkari et al. (19), as well as that conducted by Adeyemi et al. (14), are in keeping with our results. Hence, there is a need to improve contraceptive literacy in rural communities of Nigeria. This will involve an increased and sustained political will by the Nigerian government and its partner agencies to invest more on family planning education programmes to improve the knowledge-base of rural women regarding contraception. Such programmes should also be designed using all media of communication, all-inclusive and nondiscriminative strategies- to reach the underserved women and using the local languages of the rural dwellers.

As revealed in the current study, fear of perceived side effects, spousal refusal and low pregnancy risk perception were the main barriers to contraceptive use among the non-users in the study population. This findings are in congruence with the reports from previous studies $(10,20-$ 22). Contraceptive educational programme should equally target men in the rural communities for grater acceptability. Moreover, contraceptive messages will be more impactful in removing myths and misconceptions about pregnancies and family planning use if its firmly integrated in the antenatal care services.
This study may not be totally free from socialdesirability bias since most of the respondents knew the interviewers were medical students. Answers might have been given to satisfy the desire of the students. However, this bias was minimized by carefully explaining the objectives of the study to the respondents and by letting them know that their honest responses to questions were necessary for actualization of the aim of the study.

In conclusion, this study reveals a high contraceptive awareness level but low knowledge, attitude and practice. The main determinants of contraceptive uptake were knowledge, attitude and respondents' educational status. There is a need for a paradigm shift in family planning programming and delivery to rural Nigerians in order to attain the reproductive health target of SDG-3.

\section{REFERENCES}

1. United Nations. World population projected to reach 9.8 billion in 2050, and 11.2 billion in 2100 | UN DESA | United Nations Department of Economic and Social Affairs. [cited 2020 Mar 7]. Available from: https://www.un.org/development/desa/en/news/p opulation/world-population-prospects-2017.html

2. United Nations. Health - United Nations Sustainable Development. [cited 2020 Mar 7]. Available from: https://www.un.org/sustainabledevelopment/healt $\mathrm{h} /$

3. World Health Organization, UNICEF, United Nations Fund for Population Activities, World Bank, United Nations. Department of Economic and Social Affairs. Population Division. Trends in maternal mortality, 1990 to 2013: estimates by WHO, UNICEF, UNFPA, the World Bank estimates, and the United Nations Population Division. $56 \mathrm{p}$.

4. Federal Republic of Nigeria. Nigeria Demographic and Health Survey 2008. 2009 [cited 2020 Mar 7]. Available from: http://www.measuredhs.com.

5. Nigeria. NIGERIA DEMOGRAPHIC AND HEALTH SURVEY 2013 National Population Commission Federal Republic of Nigeria Abuja. 2014.

6. The Federal Republic of Nigeria Nigeria 
Demographic and Health Survey 2018 National Population Commission Abuja, Nigeria. 2019 [cited 2020 Jan 6]. Available from: www.DHSprogram.com.

7. Bankole A, Adewole IF, Hussain R, Awolude O, Singh S, Akinyemi JO. The incidence of abortion in Nigeria. Int Perspect Sex Reprod Health. 2015 Dec 1;41(4):170-81.

8. Okigbo C, Speizer I, Domino M, Curtis S. A Multilevel Logit Estimation of Factors Associated With Modern Contraception in Urban Nigeria. World Med Heal Policy. 2017 Mar 1 [cited 2020 Mar 7];9(1):65-88. Available from: http://doi.wiley.com/10.1002/wmh3.215

9. Adeyemi AS, Adekanle DA, Komolafe JO. Pattern of contraceptives choice among the married women attending the family planning clinic of a tertiary health institution. Niger J Med. 2008;17(1):67-70.

10. Asekun-Olarinmoye EO, Adebimpe WO, Bamidele JO, Odu OO, Asekun-Olarinmoye IO, Ojofeitimi EO. Barriers to use of modern contraceptives among women in an inner city area of Osogbo metropolis, Osun State, Nigeria. Int J Womens Health. 2013 Oct 10;5(1):647-55.

11. Tunau K, Awosan KJ, Adamu H, Muhammad U, Hassan M, Nasir S, et al. Comparative assessment of modern contraceptives' knowledge and utilization among women in urban and rural communities of Sokoto State, Nigeria. J Med Med Sci. 2016 [cited 2020 Mar 7];7(1):6-014. Available from: http://www.interesjournals.org/JMMS

12. FP2020. Strategy 2016-2020 | Family Planning 2020. [cited 2020 Feb 8]. Available from: http://www.familyplanning2020.org/strategy

13. National Bureau of Statistics. Federal Republic of Nigeria; Annual Abstract of Statistics. 2012. [cited 2020 Mar 7]. Available from: www.nigerianstat.gov.ng,

14. Adeyemi AS, Olugbenga-Bello AI, Adeoye OA, Salawu MO, Aderinoye AA, Agbaje MA. Contraceptive prevalence and determinants among women of reproductive age group in Ogbomoso, Oyo State, Nigeria. Open access $J$ Contracept. 2016 [cited 2020 Mar 7];7:33-41. Available from: http://www.ncbi.nlm.nih.gov/pubmed/29386935

15. Bani S, Hosseini K, Hasanpour S, Valizadeh S,
Abedi P. Awareness, Attitude and participation rate of men in family planning programs in Iran. Int $J$ Women's Heal Reprod Sci. 2014 Dec $1 ; 2(1): 17-25$.

16. Utoo BT, Mutihir TJ, Utoo PM. Knowledge, attitude and practice of family planning methods among women attending antenatal clinic in Jos, North-central Nigeria. Niger J Med. 2010 [cited 2020 Mar 7];19(2):214-8. Available from: http:/www.ncbi.nlm.nih.gov/pubmed/20642092

17. Monjok E. Contraceptive practices in Nigeria: Literature review and recommendation for future policy decisions. Open Access J Contracept. 2010 May 5;1:9.

18. Semachew Kasa A, Tarekegn M, Embiale N. Knowledge, attitude and practice towards family planning among reproductive age women in a resource limited settings of Northwest Ethiopia. BMC Res Notes. 2018 Aug 13 [cited 2020 Mar 7];11(1):577. Available from: https://bmcresnotes.biomedcentral.com/articles/1 0.1186/s13104-018-3689-7

19. Mitkari KK, Haralkar S, Sancheti P, Gokhale R. Study of contraceptive use in married women of reproductive age group in urban slum area of western Maharashtra. Int $J$ Community Med Public Heal. 2019 Sep 26;6(10):4499.

20. Durowade KA, Omokanye LO, Elegbede OE, Adetokunbo S, Olomofe CO, Ajiboye AD, et al. Barriers to Contraceptive Uptake among Women of Reproductive Age in a Semi-Urban Community of Ekiti State, Southwest Nigeria. Ethiop J Health Sci. 2017 Mar 1;27(2):121-8.

21. Muanda MF, Ndongo GP, Messina LJ, Bertrand JT. Barriers to modern contraceptive use in rural areas in DRC. Cult Health Sex. 2017 Sep 2 [cited 2020 Mar 8];19(9):1011-23. Available from: https:/www.tandfonline.com/doi/full/10.1080/13 691058.2017.1286690

22. Ochako R, Mbondo M, Aloo S, Kaimenyi S, Thompson R, Temmerman M, et al. Barriers to modern contraceptive methods uptake among young women in Kenya: A qualitative study Global Health. BMC Public Health. 2015 Dec 12 [cited 2020 Mar 8];15(1):118. Available from: http://bmcpublichealth.biomedcentral.com/article s/10.1186/s12889-015-1483-1

DOI: http://dx.doi.org/10.4314/ejhs.v30i4.8 